\title{
Agroecologia e Agricultura Familiar na Região Centro-Sul do Estado do Paraná*
}

\author{
Renato Linhares de Assis** \\ Ademar Ribeiro Romeiro***
}

Resumo: O trabalho avalia o uso de técnicas agroecológicas pela produção familiar na região centro-sul do Estado do Paraná. Utiliza-se a metodologia de diagnóstico rápido dos sistemas agrários, tendo como referência trabalho desenvolvido na região pela AS-PTA, ONG que visa o desenvolvimento de agricultores familiares a partir do fomento de tecnologias agroecológicas. Após caracterização dos sistemas de produção dos agricultores pesquisados e do ambiente social que os cerca, finaliza-se com uma avaliação dos indicadores econômicos. Verifica-se uma relação entre o grau de capitalização dos agricultores e a adoção de práticas agroecológicas, a qual aumenta à medida que se reduz o grau de capitalização, sendo menor o risco econômico da atividade agrícola dos

* Texto apresentado parcialmente no XXXIX Congresso Brasileiro de Economia e Sociologia Rural e no Encontro Internacional sobre Agroecologia e Desenvolvimento Rural Sustentável. Parte da tese de doutorado do primeiro autor.

** Engenheiro Agrônomo, Doutor em Desenvolvimento Econômico, Espaço e Meio Ambiente pelo Instituto de Economia da Universidade Estadual de Campinas, Pesquisador da Empresa Brasileira de Pesquisa Agropecuária / Centro Nacional de Pesquisa de Agrobiologia (Embrapa Agrobiologia); caixa postal 74505, CEP 23850-970, Seropédica - RJ. renato@cnpab.embrapa.br

*** Economista, Doutor em Economia pela École des Hautes Études en Sciences Sociales, Paris/França, Pesquisador Visitante na Universidade de Stanford/EUA e Professor Associado (Livre Docente) do Instituto de Economia da Universidade Estadual de Campinas (IE-Unicamp), Cidade Universitária, caixa postal 6135, CEP 13083-970, Campinas - SP. ademar@eco.unicamp.br 
agricultores com maior índice de adoção. Conclui-se que há um potencial positivo da utilização da agroecologia como instrumento para o desenvolvimento sustentável de agricultores familiares, realçando-se a importância do apoio do poder público na dinamização deste processo.

Palavras-chave: técnicas agroecológicas, agricultura sustentável, dinâmica de inovações, agricultura alternativa, políticas públicas.

Classificação JEL: 033 - mudança tecnológica; escolhas e consequências; processo de difusão.

Abstract: The paper analyzes the adoption of agro-ecological techniques by a group of small family farmers in a region of the State of Paraná. The sample of the farmers to be interviewed was obtained by applying a methodology of fast rural assessment and relied on the work of a non governmental organization (AS-PTA) that has the major responsible for the technological change in the region. A typology of producers and agrarian systems was obtained, which made it possible to evaluate the technological trajectories followed. A negative correlation was observed between the capitalization level of the farm unity and the adoption of agro-ecological techniques, suggesting that the latter are being introduced as a low risk strategy to improve the production conditions within a context of labor abundance and capital scarcity. The paper concludes that it is worth to support those farmers in their decision through more focused public policies (credit and scientific research).

Keywords: agro-ecological techniques, sustainable agriculture, innovation dynamics, alternative agriculture, public policies.

\section{JEL Classification: 033}

\section{Introdução}

A agroecologia é uma ciência que resgata o conhecimento agrícola tradicional desprezado pela agricultura moderna, e procura fazer sua sistematização e validação de forma que este possa ser (re)aplicado em novas bases 
(científicas). Além disto, na medida que expressa em seus princípios, que para sua prática é necessário um ser humano desenvolvido e consciente, com atitudes de coexistência e não de exploração para com a natureza (Altieri, 1989), a agroecologia se apresenta no Brasil como uma forma de resistência contra a devastadora onda modernizadora e contra a expropriação completa dos agricultores (Canuto, 1998). O que integra propostas agroecológicas com outras voltadas a desenvolver a agricultura familiar.

Em função de suas especificidades, a organização social da produção agrícola baseada no trabalho familiar favorece a conciliação entre a complexificação desejada e a supervisão e controle do processo de trabalho necessário, de tal forma que Carmo (1998) a considera como o locus ideal ao desenvolvimento de uma agricultura ambientalmente sustentável, em função de suas características de produção diversificada, integrando atividades vegetais e animais, e por trabalhar em menores escalas.

A estrutura familiar de produção não representa uma limitação ao desenvolvimento agrícola, mas sim que este deva ocorrer a partir de uma lógica diferente, na medida em que - como enfatiza Brandenburg (1999) - os âmbitos da satisfação, do desejo ou da subjetivação, que justificam a conduta dos agricultores, nem sempre atuam de forma dissociada como nos demais sistemas da sociedade moderna. Esta lógica é que faz com que Costa Neto (1999) apresente uma estrutura social agrária com base na unidade familiar e o conseqüente trabalho agrícola associativo e cooperado, aliado à preocupação ambiental, inerente a agroecologia, como embrião do surgimento no campo de uma sociedade verdadeiramente sustentável.

Partindo destas premissas pretende-se neste trabalho avaliar a viabilidade de modelos agroecológicos de produção como instrumento para o desenvolvimento de agricultores familiares, assim como avaliar a importância de políticas públicas específicas neste processo. Para isto tomar-se-á como base estudo de caso junto a produtores familiares de milho e feijão, tendo por referência trabalho desenvolvido na região centro-sul do Estado do Paraná pela AS-PTA (Assessoria e Serviços a Projetos em Agricultura Alternativa), ONG que tem por objetivo o desenvolvimento de agricultores familiares a partir do fomento de tecnologias agroecológicas.

Inicialmente apresenta-se a metodologia utilizada, para em seguida expor-se às características gerais da região centro-sul do Estado do 
Paraná e de sua agricultura familiar. Discutem-se então as informações obtidas através de entrevistas junto a agricultores familiares da região em questão, na seguinte ordem: práticas agroecológicas e os sistemas de produção observados; os agricultores pesquisados e o ambiente social que os cerca (condições de vida, organização social e ação do poder público); e indicadores econômicos dos agricultores entrevistados, para finalizar com uma conclusão acerca do objetivo proposto.

\section{Metodologia utilizada}

Para a caracterização dos sistemas agrários predominantes na região centro-sul do Paraná, optou-se por utilizar a metodologia de diagnóstico rápido dos sistemas agrários, apresentada por Garcia Filho (2003), como a melhor forma de estabelecer os parâmetros para amostragem dos agricultores a serem entrevistados e atingir os objetivos propostos.

Trata-se de uma metodologia que parte do geral para o particular, do nível microrregional até o estabelecimento agrícola, permitindo compreender a "racionalidade" dos atores locais representativos a partir de um enfoque sistêmico; a partir de então, torna-se possível fazer generalizações capazes de subsidiar propostas de políticas agrícolas para a melhoria das condições sócio-econômicas dos agricultores familiares. Em cada etapa, os fenômenos devem ser interpretados e confrontados com as análises das etapas anteriores e, ao final, elaboram-se as hipóteses que devem ser verificadas na etapa seguinte. Assim, constrói-se progressivamente uma síntese cada vez mais aprofundada da realidade observada. Como existe um grande número de variáveis que pode influenciar o desenvolvimento rural, é importante não perder-se nos detalhes e manter sempre uma visão global do objeto de estudo.

É importante assinalar que o método visa explicar e não somente descrever os fenômenos observados. Para isso, é necessário manter a perspectiva histórica em todas as etapas do método e realizar uma avaliação econômica dos diferentes sistemas de produção, tanto do ponto de vista do agricultor quanto do ponto de vista da sociedade. Como, em geral, as realidades agrárias são marcadas pela diversidade, é preciso fazer um esforço de estratificação da realidade, estabelecendo conjuntos homogêneos e contrastados, definidos de acordo com o desenvolvimento 
rural - tipologias de sistemas de produção e de produtores. Além disso, é fundamental também evidenciar os mecanismos que produziram esta diferenciação, sejam eles ecológicos ou sociais. Não basta estudar cada uma das partes ou dos fenômenos da realidade agrária que se quer conhecer. É necessário entender as relações entre as partes e entre os fatos ecológicos, técnicos e sociais que explicam a realidade. O estudo dos solos, por exemplo, só é relevante quando relacionado com as técnicas utilizadas ou com os problemas enfrentados pelos agricultores.

A primeira etapa do método consiste no que é chamado de "leitura de paisagem”, quando o pesquisador percorre a região a ser estudada observando suas características gerais de solo, vegetação, e tudo o mais que possa ser apreendido visualmente. Pressupõe-se que antes de partir para esse percurso o pesquisador tenha se municiado de todas as informações disponíveis sobre a região (censos, relatórios de pesquisa, etc.).

A segunda etapa consiste na implementação de um processo de amostragem dirigida: entrevistas com atores-chave, definidos como tais pela importância de sua inserção e conhecimentos da região - agentes extensionistas, gerentes de crédito rural, representantes de firmas agropecuárias, ONGs, etc. O tamanho da amostra é, pois, determinado sobretudo pela complexidade e pela diversidade da realidade estudada. Não se trabalha, portanto, com amostragens aleatórias, pois elas não asseguram, justamente por seu caráter intrínseco, a representação e a análise aprofundada de toda esta diversidade. No caso desta pesquisa, papel especial teve a ONG AS-PTA.

A terceira etapa consiste na definição, com base nestas entrevistas, de uma amostra segundo uma pré-tipologia de sistemas de produção e de produtores, bem como sua distribuição espacial. Trata-se, portanto, de uma amostra não-probabilistica, mas representativa dos principais sistemas de produção e dos tipos de agricultores da região e que possui ainda a vantagem de permitir a aplicação de questionários abertos mais detalhados e, desse modo, extrair mais informações sobre a dinâmica das trajetórias de acumulação e de mudança tecnológica dos agentes produtivos.

Destarte, o tamanho da amostra para entrevistas foi de 36 agricultores, distribuída entre 6 agricultores em 6 municípios selecionados (na análise dos dados este total foi reduzido a 35 devido à perda das informações de uma entrevista). A seleção dos produtores em cada município foi feita a partir de entrevistas com lideranças locais contatadas, tendo como 
critério básico a existência de experiência com práticas agroecológicas. Procurou-se também estratificar os agricultores em função do nível de capitalização (2 capitalizados, 2 em vias de capitalização, e 2 descapitalizados). Assim, a escolha dos agricultores a serem entrevistados foi feita a partir do entendimento que estas lideranças locais fizeram da explicação do que seriam estes níveis de capitalização, o que foi feito da seguinte forma: agricultores capitalizados seriam aqueles cuja atividade agrícola estaria tendo resultado econômico ${ }^{1}$ superior a duas vezes o custo de oportunidade do trabalho ${ }^{2}$; agricultores em vias de capitalização seriam os que estariam tendo um resultado econômico superior a uma vez até duas vezes o custo de oportunidade do trabalho; e agricultores descapitalizados seriam os cuja atividade agrícola estaria proporcionando um resultado econômico entre o nível de subsistência e o custo de oportunidade do trabalho (Guanziroli et al., 2000).

As entrevistas foram feitas utilizando-se um roteiro com perguntas que permitiam respostas abertas, tendo sido estas agrupadas e tabuladas posteriormente, em função da idéia geral do pensamento apresentado pelos agricultores em relação a cada ponto que foi questionado.

\section{A região centro-sul do Estado do Paraná e a agricultura familiar}

A região centro-sul do Paraná também conhecida como Paraná Tradicional, por ter sido onde se deu o início da ocupação do estado, tem cerca de 1.300.000 ha distribuídos por 20 municípios com uma grande concentração de agricultores familiares. No que se refere a sua caracterização, a região apresenta a Serra da Esperança como seu marco geográfico principal, a qual delimita o segundo planalto (a leste) do terceiro planalto paranaense (a oeste), e divide a região no sentido leste-oeste. Esta característica do meio físico serve de marco para diferenças gerais marcantes entre os municípios da região separados pela mesma. A maioria (14) estão localizados a leste da Serra da Esperança, e são eles: Antônio Olinto, Guamiranga, Imbituva,

\footnotetext{
${ }^{1} \mathrm{O}$ resultado econômico refere-se à renda líquida por unidade de trabalho.

${ }^{2}$ Considerou-se o salário mínimo como referência para o custo de oportunidade do trabalho.
} 
Irati, Lapa, Mallet, Paula Freitas, Palmeira, Paulo de Frontin, Rebouças, Rio Azul, São João do Triunfo, São Mateus do Sul, e Teixeira Soares. Cinco municípios estão localizados a oeste: Bituruna, Cruz Machado, General Carneiro, Inácio Martins, e Porto Vitória. Um último município, União da Vitória, caracteriza-se por uma divisão aproximadamente equânime, com parte tanto a leste como a oeste da referida serra.

Observa-se que a região a oeste da Serra da Esperança caracteriza-se por uma topografia forte ondulada a montanhosa com elevadas restrições à mecanização, limitando-se as áreas planas a várzeas e planícies isoladas. Os solos nesta região apresentam textura argilosa, o que minimiza as perdas por erosão favorecida pela forte declividade. Predominam os neossolos litólicos e os cambissolos, com a ocorrência também de algumas manchas de nitossolos álicos.

A leste da Serra da Esperança a topografia caracteriza-se em sua maior parte como ondulada a forte ondulada, predominando cambissolos álicos, argissolos vermelho-amarelo álicos e nitossolos. Nas partes mais planas aparecem também áreas com latossolos vermelho escuro álicos. Apesar da topografia menos acidentada, esta região tende a ser mais suscetível à erosão em função das características de textura média apresentada pelos cambissolos e principalmente pelos podzólicos (presença de horizonte B textural). Além disto, a desuniformidade das pendentes dificulta o uso de práticas mecânicas de conservação do solo.

Destarte, a Assessoria e Serviços a Projetos em Agricultura Alternativa (AS-PTA), organização não governamental fundada em 1989 no Rio de Janeiro, com o objetivo de contribuir para a implantação no Brasil de um modelo de desenvolvimento agrícola sustentável, fundado no paradigma técnico-científico da agroecologia, iniciou em 1993 atuação junto a agricultores familiares da região cento-sul do Estado do Paraná, procurando introduzir práticas agroecológicas nas unidades de produção familiar, considerando que estas práticas, ao maximizarem o uso da mão-de-obra e reduzirem a necessidade de insumos externos, maximizam os recursos disponíveis na agricultura familiar, apresentar-se-iam como um instrumento viável para o estabelecimento de um processo de desenvolvimento agrícola sustentável.

Sendo assim, tomando-se como base o trabalho desenvolvido na região pela AS-PTA, verifica-se que em 8 municípios há uma forte atuação desta ONG: Bituruna, Cruz Machado, Imbituva, Irati, Palmeira, Rebouças, 
Rio Azul, e São João do Triunfo. Agregando-se esta informação ao diagnóstico apresentado da região, na seleção dos agricultores entrevistados, foram considerados os seguintes fatores: localização a leste ou a oeste da Serra da Esperança; características sócio-econômicas como percentual de agricultores familiares e quantos destes produzem feijão e milho (Tabela 1); localização em município com forte atuação da AS-PTA; e existência de política municipal voltada à difusão de práticas agroecológicas junto a agricultores familiares.

Assim, considerando primeiramente os municípios com forte atuação da AS-PTA, a oeste da Serra da Esperança, Cruz Machado e Bituruna foram selecionados em função de possuírem o maior percentual de agricultores familiares, ao mesmo tempo em que mantém altos índices de produtores de feijão e milho. Da mesma forma, utilizando os mesmos critérios, no lado leste a escolha recaiu sobre Rebouças e Rio Azul. Em acréscimo, incluíram-se os municípios de Palmeira e União da Vitória, em função de que nestes estavam sendo implementadas políticas públicas com base na agroecologia, representando oportunidade de avaliar a importância do poder público na difusão de modelos agroecológicos de produção.

\section{Organização social e a ação do poder público}

O nível de organização dos agricultores apresenta-se como extremamente elevado na região, tendo sido ponto fundamental para a AS-PTA na escolha desta como área de atuação. O destaque é para a atuação dos sindicatos dos trabalhadores rurais, que tem funcionado como elo de ligação entre a AS-PTA e os agricultores. Como resultado então da interação entre estas instituições, percebe-se na Tabela 2 que, na avaliação que os entrevistados fazem da atuação do sindicato, a difusão da agroecologia, que vislumbram como forma de implementarem um desenvolvimento sustentável do ambiente em que vivem, recebe o mesmo destaque que a organização e defesa dos interesses de classe mais gerais, função precípua do sindicato.

Esta ação do sindicato enquanto órgão de defesa de classe tem sido complementada pelas associações comunitárias existentes na opinião de parte dos agricultores, aumentando os mecanismos de pressão sobre o poder público, mas possuem função principal, na opinião da maioria, como órgão que favorece uma maior rentabilidade da agricultura ao criar 
mecanismos comerciais alternativos (para venda da produção e compra de insumos) bem como com estruturas comunitárias de beneficiamento da produção, agregando valor a esta (Tabela 3).

Tabela 1: Distribuição percentual da produção agrícola familiar nos municípios da região centro-sul do Estado do Paraná.*

\begin{tabular}{lcccc}
\hline \multicolumn{1}{c}{ Município } & $\begin{array}{c}\text { Agricultores } \\
\text { familiares }\end{array}$ & $\begin{array}{c}\text { Área ocupada } \\
\text { pela agricultura } \\
\text { familiar }\end{array}$ & $\begin{array}{c}\text { Agricultores } \\
\text { familiares } \\
\text { produtores de } \\
\text { Rebouças }\end{array}$ & $\begin{array}{c}\text { Agricultores } \\
\text { familiares }\end{array}$ \\
\cline { 2 - 2 } Rio Azul & 97,0 & 82,8 & 82,7 & $\begin{array}{c}\text { fadutores de } \\
\text { milho }\end{array}$ \\
Paulo de Frontin & 96,8 & 88,4 & 80,6 & 80,5 \\
Guamiranga & 96,4 & 70,62 & 72,7 & 89,3 \\
Irati & 96,4 & 75,8 & 61,9 & 84,7 \\
Mallet & 95,5 & 78,1 & 86,3 & 59,8 \\
Antônio Olinto & 94,8 & 78,6 & 85,5 & 84,7 \\
Imbituva & 94,5 & 65,2 & 90,0 & 89,4 \\
São Mateus do Sul & 94,2 & 59,5 & 58,6 & 85,6 \\
São João do Triunfo & 93,9 & 54,8 & 74,4 & 77,1 \\
Paula Freitas & 92,7 & 55,3 & 68,4 & 73,0 \\
Lapa & 90,0 & 43,3 & 64,9 & 82,0 \\
Teixeira Soares & 89,9 & 28,2 & 76,9 & 78,0 \\
Palmeira & 88,8 & 40,1 & 54,1 & 77,2 \\
Fernandes Pinheiro & 85,9 & 29,0 & 38,7 & 60,1 \\
União da Vitória & 87,9 & 38,0 & 78,0 & 82,5 \\
Cruz Machado & 97,2 & 71,4 & 64,8 & 70,6 \\
Bituruna & 93,1 & 52,3 & 94,1 & 95,4 \\
Inácio Martins & 89,0 & 33,3 & 77,7 & 92,7 \\
Porto Vitória & 84,7 & 67,2 & 62,7 & 70,0 \\
General Carneiro & 76,5 & 16,8 & 65,8 & 81,9 \\
\hline
\end{tabular}

* Fonte: DESER (1999) a partir do Censo Agropecuário 1995/96 - IBGE 
Tabela 2: Avaliação dos agricultores familiares da região centro-sul do Estado do Paraná entrevistados, da função desempenhada pelo sindicato $(\mathrm{n}=35)$. $^{*}$

\begin{tabular}{|c|c|}
\hline Avaliação** & $\mathrm{N}^{\mathrm{o}}$. de agricultores \\
\hline - É importante e tem auxiliado: & 29 \\
\hline $\begin{array}{l}\text { Difundindo a agroecologia, viabilizando o desenvolvimento } \\
\text { sustentável dos agricultores }\end{array}$ & 17 \\
\hline $\begin{array}{l}\text { Organizando e defendendo os interesses dos agricultores } \\
\text { familiares }\end{array}$ & 17 \\
\hline $\begin{array}{l}\text { Orientando em questões legais e na obtenção de } \\
\text { documentos }\end{array}$ & 7 \\
\hline Orientando na obtenção de crédito agrícola (PRONAF) & 2 \\
\hline Somente com assistência médica & 1 \\
\hline - É importante mas não tem auxiliado e deveria ajudar: & 3 \\
\hline $\begin{array}{l}\text { Auxiliando na viabilização de canais alternativos de } \\
\text { comercialização }\end{array}$ & 1 \\
\hline $\begin{array}{l}\text { Organizando e defendendo os interesses dos agricultores } \\
\text { familiares }\end{array}$ & 1 \\
\hline Com informações técnicas agroecológicas & 1 \\
\hline Na obtenção de insumos alternativos & 1 \\
\hline - Não considera importante & 3 \\
\hline - Total & 35 \\
\hline
\end{tabular}

* Fonte: Dados da pesquisa. ${ }^{* *}$ Respostas não excludentes.

No que se refere à cooperativa, os agricultores consideram ser uma entidade com função semelhante à da associação, só que com uma estrutura maior, no que se refere às funções de comercialização da produção, aquisição de insumos e beneficiamento da produção (Tabela 4). Estas funções, porém, não vem sendo desempenhadas satisfatoriamente, ou por ineficiência ou por não existirem, sendo uma instituição desgastada junto aos entrevistados em função de experiências anteriores mal sucedidas, em que estes não tiveram seus anseios atendidos, considerando então a associação mais interessante na medida que, com uma estrutura menor, estabelece uma proximidade que permite maior participação nas tomadas de decisões, fazendo com que esta entidade tenha suas funções ampliadas em relação às da cooperativa (Tabelas 3 e 4).

É interessante ainda observar que tanto a associação como a cooperativa não são entidades percebidas pelos agricultores como importantes na difusão de práticas agroecológicas. Considera-se isto resultado do trabalho da AS-PTA junto às comunidades que, como já citado, dá-se via sindicato que, de certa forma, tem cumprido na região parte das funções que a princípio seriam da associação ou da cooperativa. 
Tabela 3: Avaliação dos agricultores familiares da região centro-sul do Estado do Paraná entrevistados, da função desempenhada pela associação ( $\mathrm{n}=35)$. ${ }^{*}$

\begin{tabular}{|c|c|}
\hline Avaliação** & $\mathrm{N}^{\circ}$. de agricultores \\
\hline - É importante e tem auxiliado: & 25 \\
\hline Na comercialização da produção & 9 \\
\hline Na compra de insumos & 7 \\
\hline Na orientação técnica & 3 \\
\hline No intercâmbio de experiências & 1 \\
\hline Na socialização de informações & 1 \\
\hline No beneficiamento da produção em estrutura comunitária & 8 \\
\hline Com estrutura comunitária de máquinas agrícolas & 2 \\
\hline Em trabalhos comunitários & 3 \\
\hline Aumentando o poder de negociação junto ao poder público & 8 \\
\hline - É importante mas não tem auxiliado e deveria ajudar: & 8 \\
\hline Na comercialização da produção & 3 \\
\hline Na compra de insumos & 2 \\
\hline Com estrutura comunitária de beneficiamento da produção & 4 \\
\hline Reforçando as ações do sindicato & 2 \\
\hline Aumentando o poder de negociação junto ao poder público & 1 \\
\hline Na socialização de informações & 1 \\
\hline Em trabalhos comunitários & 1 \\
\hline Com orientação técnica agroecológica & 1 \\
\hline - Não considera importante & 2 \\
\hline - Total & 35 \\
\hline
\end{tabular}

* Fonte: Dados da pesquisa. ** Respostas não excludentes.

Na Tabela 5 é apresentada a avaliação dos agricultores em relação à Emater, sendo alto o índice de insatisfação (17 entrevistados $=48,6$ \%) com a atuação desta instituição na região, a qual é caracterizada por atendimento em grupos, vinculando-se visitas técnicas à solicitação específica ou ao uso de crédito agrícola (acompanhamento de projeto técnico). Essa insatisfação deve-se não apenas às dificuldades de atendimento (de receber a visita), mas também à qualidade deste, no sentido em que considera-se que os técnicos desta instituição não possuem formação que permita-lhes oferecer assistência técnica numa linha agroecológica, o que, aliado ao fato de que a linha agroquímica adotada exige uma capitalização mínima do agricultor, exclui duplamente boa parte dos agricultores estudados da assistência técnica oficial em função da inadequação da linha tecnológica predominante na Emater. 
Tabela 4: Avaliação dos agricultores familiares da região centro-sul do Estado do Paraná entrevistados, da função desempenhada pela cooperativa $(\mathrm{n}=35)$. $^{*}$

\begin{tabular}{|c|c|}
\hline Avaliação** & $\mathrm{N}^{\circ}$. de agricultores \\
\hline - Existe uma na região e é importante: & 5 \\
\hline Possibilitando estabilidade ao preco dos produtos agrícolas & 4 \\
\hline Na compra de insumos mais baratos & 3 \\
\hline Motivo não explicitado & 1 \\
\hline - Existe uma na região mas não é importante: & 4 \\
\hline $\begin{array}{l}\text { Porque pequeno produtor não tem espaço neste tipo de } \\
\text { estrutura }\end{array}$ & 3 \\
\hline Motivo não explicitado & 1 \\
\hline - Não existe uma na região mas seria importante: & 11 \\
\hline Possibilitando estabilidade ao preço dos produtos agrícolas & 7 \\
\hline Na compra de insumos mais baratos & 6 \\
\hline No beneficiamento da produção & 4 \\
\hline Na assistência técnica agroecológica & 1 \\
\hline Aproximando o crédito agrícola do agricultor & 1 \\
\hline - Não existe uma na região e não seria importante: & 15 \\
\hline $\begin{array}{l}\text { Porque pequeno produtor não tem espaço neste tipo de } \\
\text { estrutura }\end{array}$ & 2 \\
\hline Associação cumpre o papel de uma cooperativa & 1 \\
\hline Motivo não explicitado & 12 \\
\hline - Total: & 35 \\
\hline
\end{tabular}

* Fonte: Dados da pesquisa. ${ }^{* *}$ Respostas não excludentes.

Observa-se, portanto, uma deficiência estrutural no que se refere à difusão de conhecimentos científicos e tecnológicos que reflete a própria lacuna ainda existente nos sistemas públicos de pesquisa agronômica. Entre estes, cabe assinalar que a Embrapa vem procurando eliminar essa lacuna com a criação de centros de pesquisa de referência em agroecologia e meio ambiente, que deverão orientar as pesquisas de todas as demais unidades da empresa.

No que se refere à ação do poder público municipal, observamos pela Tabela 6 que este, de uma forma geral, é considerado pouco presente, contribuindo somente com insumos (sementes/calcário) e/ou aluguel subsidiado de máquinas, além de atuação mais geral na manutenção de estradas. A exceção desta avaliação refere-se aos municípios de União da Vitória e Palmeira que, por ocasião das entrevistas, possuíam políticas municipais específicas de incentivo à agroecologia, e onde os agricultores destacaram, em acréscimo às funções semelhantes observadas nos outros municípios desempenhadas pelo poder público municipal, a importância deste no processo de adoção da agroecologia. 
O destaque nestes municípios é para o fornecimento de assistência técnica de rotina habilitada na linha agroecológica, e para a viabilização de canais alternativos de comercialização da produção (Tabela 6). A importância de assistência técnica com competência em agroecologia, levantada por estes agricultores, é um resultado que reforça o observado em relação à Emater relativo à inadequação da sua linha tecnológica para atuar na difusão de práticas agroecológicas (Tabela 5).

Tabela 5: Avaliação dos agricultores familiares da região centro-sul do Estado do Paraná entrevistados, da função desempenhada pela Emater $(\mathrm{n}=35)$.*

\begin{tabular}{l|c}
\hline \multicolumn{1}{c}{ Avaliação** } & No. de agricultores \\
\hline Está satisfeito & 5 \\
Não é atendido na forma de visita técnica de rotina, somente mediante & 29 \\
solicitação & 17 \\
Não está satisfeito & 6 \\
Não atendem mesmo mediante solicitação & 8 \\
Trabalha com grupo de agricultores & 7 \\
Visita técnica de rotina vinculada ao uso de crédito agrícola & 5 \\
Diretrizes políticas é que determinam o tipo de agricultor a ser & \\
atendido & 12 \\
Atendimento só na linha agroquímica/tecnologias caras e/ou técnicos \\
não possuem competência para orientar na linha agroecológica
\end{tabular}

* Fonte: Dados da pesquisa. ** Respostas não excludentes.

Tabela 6: Avaliação, por município, dos agricultores familiares da região centro-sul do Estado do Paraná entrevistados, da função desempenhada pelo poder público municipal $(\mathrm{n}=35)$. $^{*}$

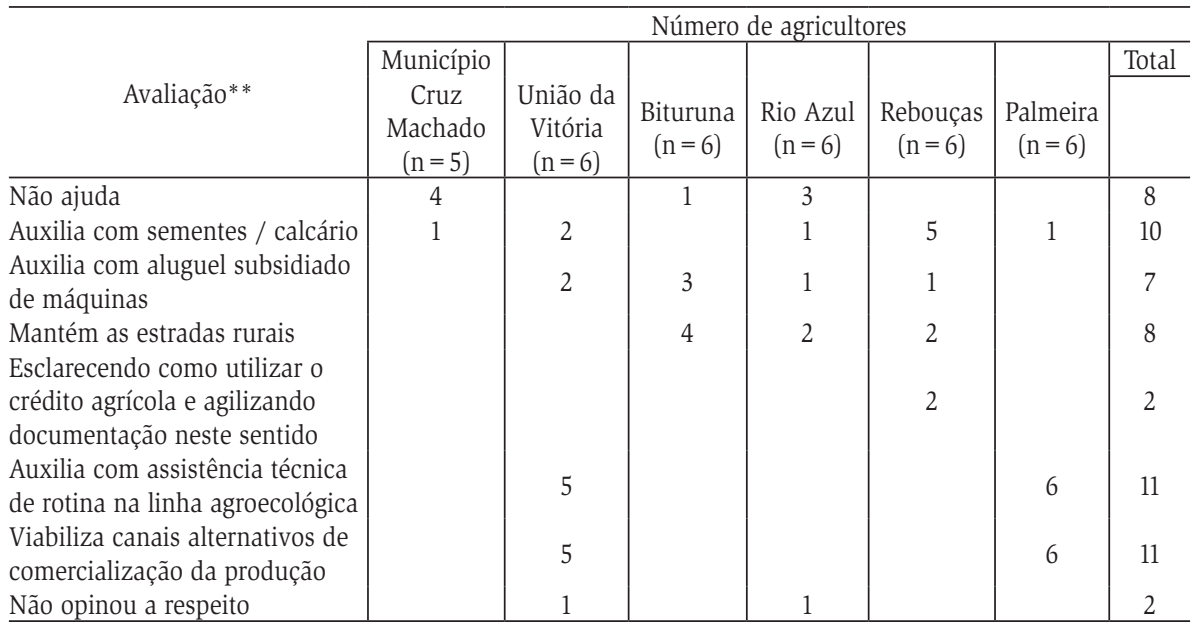

* Fonte: Dados da pesquisa. ** Respostas não excludentes. 
Em relação a canais alternativos de comercialização, o destaque dado pelos agricultores de União da Vitória e Palmeira deve-se não só à possibilidade de comercialização em mercados de produtos orgânicos, viabilizada pelo poder público destes municípios, como também àquela de comercialização em mercado local, através de feiras. Esta mostrou-se interessante para os agricultores na medida em que possibilitou-lhes uma redução no custo da comercialização ao retirar a figura do "atravessador" e estabelecer um contato direto entre produtores e consumidores.

A reflexão que se pode fazer desta avaliação dos agricultores em relação à atuação dos municípios é perguntar sobre as possibilidades e limites da atuação destes na viabilização da expansão dessas novas práticas agrícolas. Parece claro que os municípios poderão ter um papel ainda maior na difusão tecnológica, considerando-se as mudanças - ao que tudo indica, definitivas - do papel e alcance dos serviços estaduais de extensão rural. É preciso considerar também que este papel no momento, em particular neste caso, está condicionado pelas peculiaridades da produção alternativa de modo geral. A expectativa dos agricultores é de que a produção agroecológica no país possa caminhar de modo semelhante à produção convencional moderna no sentido de uma maior independência das políticas públicas para se capitalizar, como mostram as tabelas a seguir.

Neste sentido, no que se refere ao crédito agrícola, a Tabela 7 apresenta a avaliação dos agricultores entrevistados em relação a este instrumento de política agrícola. Observa-se nesse caso que apesar de 18 agricultores (51,4 \% dos entrevistados) não utilizarem crédito agrícola, entre os 17 agricultores que utilizam-no (48,6 \%) há uma avaliação positiva de 15 agricultores (88,2 \% dos que recorrem ao financiamento agrícola) em relação ao crédito de custeio do Programa Nacional de Apoio à Agricultura Familiar (Pronaf), o qual consideram adequado à realidade do agricultor familiar, basicamente em função do desconto que podem obter no caso de efetuarem o pagamento dentro do prazo.

Apesar desta avaliação positiva do mecanismo de crédito agrícola do Pronaf, 10 entrevistados (29 \%) ressaltaram que o desejo maior é de trabalhar com recursos próprios a partir de um processo de valorização da agricultura que resulte na sua capitalização, conforme pode ser confirmado nas Tabelas 8 e 9. 
Tabela 7: Avaliação do crédito agrícola por parte dos agricultores familiares da região centro-sul do Estado do Paraná entrevistados $(n=35)$ *

\begin{tabular}{l|c}
\multicolumn{1}{c}{ Avaliação** } & $\begin{array}{c}\text { No. de } \\
\text { agricultores }\end{array}$ \\
\hline $\begin{array}{l}\text { Sempre utilizou sem problemas } \\
\text { Não utiliza por considerar o risco / taxa de juros muito elevado }\end{array}$ & 4 \\
$\begin{array}{l}\text { Deixou de usar por considerar o nível de exigências muito elevado } \\
\text { (perde muito tempo indo à cidade várias vezes) }\end{array}$ & 4 \\
$\begin{array}{l}\text { Atualmente usa o Pronaf, que considera um mecanismo de crédito } \\
\text { adequado à realidade do agricultor familiar em função do desconto } \\
\text { que pode obter no caso de pagar dentro do prazo }\end{array}$ & 15 \\
$\begin{array}{l}\text { Recurso financeiro sai atrasado, não respeitando o tempo da } \\
\text { agricultura }\end{array}$ & 1 \\
$\begin{array}{l}\text { Perdeu crédito devido a problema em financiamento anterior } \\
\text { Ideal é poder trabalhar com recurso próprio, o que é possível com } \\
\text { preço adequado para venda da produção / mercado de produtos } \\
\text { orgânicos }\end{array}$ & 4 \\
Projeto técnico vincula sua prática agrícola ao modelo agroquímico & 10 \\
\hline
\end{tabular}

* Fonte: Dados da pesquisa. ** Respostas não excludentes.

Tabela 8: Avaliação das dificuldades da atividade agrícola por parte dos agricultores familiares da região centro-sul do Estado do Paraná entrevistados $(\mathrm{n}=35)$.*

\begin{tabular}{l|c}
\hline \multicolumn{1}{c}{ Dificuldades** $^{* *}$ No $^{\circ}$ de agricultores } \\
\hline $\begin{array}{l}\text { Estruturas de comercialização manipuladas por atravessadores/ } \\
\text { preços baixos }\end{array}$ & 28 \\
Preços muito altos dos insumos e máquinas agrícolas & 10 \\
Alto custo de produção & 9 \\
Falta de assistência técnica & 2 \\
Falta de apoio governamental à agricultura de uma forma geral & 4 \\
Falta de mecanismos de crédito agrícola adequados à & 2 \\
agricultura familiar & 3 \\
Pouca disponibilidade de terra agricultável & 1 \\
Pressão das indústrias fumageiras para que utilize o pacote & \\
agroquímico & \\
\hline
\end{tabular}

* Fonte: Dados da pesquisa. ** Respostas não excludentes.

Na Tabela 8 observa-se que os agricultores, ao informarem as principais dificuldades que enfrentam na agricultura, o destaque vai para questões relacionadas à eficiência econômica desta atividade como comercialização e custo da produção, enquanto que na Tabela 9, 15 agricultores (43 \%) levantaram a necessidade de política de preço mínimo eficiente e efetiva 
como forma de garantir esta eficiência econômica e assim suplantar as dificuldades levantadas. Afora isto pode-se ressaltar a conscientização de parte dos entrevistados da importância deles enquanto atores principais de um processo de desenvolvimento rural sustentável, sendo colocada a importância da união dos agricultores ( 9 entrevistados $=26 \%$ ), de sistemas de produção agroecológicos no aumento da eficiência econômica (6 entrevistados $=17 \%$ ), e da utilização de mercados alternativos (5 entrevistados $=14 \%$ ), como forma deles terem a iniciativa neste processo, e não ficarem totalmente à mercê de iniciativas do poder público.

Tabela 9: Possíveis soluções levantadas pelos agricultores familiares da região centro-sul do Estado do Paraná entrevistados, para as dificuldades que enfrentam com a atividade agrícola $(\mathrm{n}=35)$ * $^{*}$

\begin{tabular}{l|c}
\hline \multicolumn{1}{c}{ Solução** } & No $^{*}$ de agricultores \\
\hline $\begin{array}{l}\text { Adoção de sistemas de produção agroecológicos que reduzem } \\
\text { custos e/ou possibilitam melhores preços }\end{array}$ & 6 \\
$\begin{array}{l}\text { Melhor utilização do mercado consumidor local / mercados } \\
\text { alternativos }\end{array}$ & 5 \\
Apoio governamental a sistemas de produção agroecológicos & 1 \\
União dos agricultores & 9 \\
Política de preços mínimos justa e que seja aplicada & 15 \\
efetivamente & \\
Crédito de investimento subsidiado & 3 \\
Crédito de custeio adequado à realidade da agricultura familiar & 3 \\
Apoio governamental a estruturas comunitárias de & 3 \\
beneficiamento da produção & \\
Reforma agrária efetiva que fortaleça a agricultura familiar & 2 \\
Apoio governamental à agricultura de uma forma geral & 3 \\
Acabar com a corrupção, moralizando a área política & 1 \\
Desvincular-se das indústrias fumageiras & 1 \\
Não opinou & 4 \\
\hline
\end{tabular}

* Fonte : Dados da pesquisa. ${ }^{* *}$ Respostas não excludentes.

Do exposto, depreende-se que o processo de difusão da agroecologia na região centro-sul do Estado do Paraná, tem sua alavanca inicial baseada em iniciativa da própria sociedade, através da atuação conjunta dos sindicatos de trabalhadores rurais e da AS-PTA, resultando em experiências interessantes a ponto de despertar interesse junto a poderes públicos municipais. A ação destes então, com políticas específicas voltadas à difusão de práticas agroecológicas, tem possibilitado um resultado ampliado no que diz respeito à adoção da agroecologia por parte dos 
agricultores, e o estabelecimento de um processo de desenvolvimento rural sustentável com base nesta premissa tecnológica.

\section{Nível de capitalização dos agricultores familiares da região centro-sul do Estado do Paraná, segundo os tipos definidos pelo grau de utilização de práticas agroecológicas:}

Com base nas respostas ao questionário, os agricultores entrevistados foram agrupados em três classes de acordo com o grau de utilização de práticas agroecológicas: tipo (1) - alto; tipo (2) - médio; e tipo (3) - baixo. Posteriormente estas classes foram subdividas em função da utilização (A) ou não (B) de canais de comercialização de produtos orgânicos e em função da não utilização (X) de adubação mineral e/ou agrotóxico, da utilização (Y) de adubação mineral sem agrotóxicos e da utilização $(\mathbf{Z})$ de adubação mineral e agrotóxicos. Entre as diferentes combinações possíveis a partir desta classificação, foram observados 7 tipos diferentes (Quadro 1)

Quadro 1: Tipologia, a partir do grau de utilização de práticas agroecológicas, dos agricultores familiares da região centro-sul do Estado do Paraná entrevistados.

\begin{tabular}{|c|c|l|}
\hline Tipologia & $\begin{array}{c}\text { N}^{0} \text { de } \\
\text { agricultores }\end{array}$ & \multicolumn{1}{c|}{ Descrição } \\
\hline $\mathbf{1 A X}$ & 8 & $\begin{array}{l}\text { Alto índice de utilização de práticas agroecológicas, com comercialização } \\
\text { parcial da produção em mercados de produtos orgânicos, e sem } \\
\text { utilização de adubação mineral e/ou agrotóxicos. }\end{array}$ \\
\hline $\mathbf{1 B X}$ & 2 & $\begin{array}{l}\text { Alto índice de utilização de práticas agroecológicas, sem utilização de } \\
\text { canais de comercialização de produtos orgânicos, e sem utilização de } \\
\text { adubação mineral e/ou agrotóxicos. }\end{array}$ \\
\hline $\mathbf{1 B Y}$ & 3 & $\begin{array}{l}\text { Alto índice de utilização de práticas agroecológicas, sem utilização de } \\
\text { canais de comercialização de produtos orgânicos, e com utilização de } \\
\text { adubação mineral e sem utilização de agrotóxicos. }\end{array}$ \\
\hline $\mathbf{2 A Y}$ & 6 & $\begin{array}{l}\text { Médio índice de utilização de práticas agroecológicas, com comerciali- } \\
\text { zação parcial da produção em mercados de produtos orgânicos, e com } \\
\text { utilização de adubação mineral e sem utilização de agrotóxicos. }\end{array}$ \\
\hline $\mathbf{2 B Z}$ & 2 & $\begin{array}{l}\text { Médio índice de utilização de práticas agroecológicas, sem utilização } \\
\text { de canais de comercialização de produtos orgânicos, e com utilização } \\
\text { de adubação mineral e sem utilização de agrotóxicos. }\end{array}$ \\
\hline $\mathbf{3 B Z}$ & 5 & $\begin{array}{l}\text { Médio índice de utilização de práticas agroecológicas, sem utilização } \\
\text { de canais de comercialização de produtos orgânicos, e com utilização } \\
\text { de adubação mineral e de agrotóxicos. }\end{array}$ \\
\hline & $\begin{array}{l}\text { Baixo índice de utilização de práticas agroecológicas, sem utilização } \\
\text { de canais de comercialização de produtos orgânicos, e com utilização } \\
\text { de adubação mineral e de agrotóxicos. }\end{array}$ \\
\hline
\end{tabular}


Utilizando-se então esta tipologia elaborou-se a Tabela 10 onde são apresentados os valores médios de rendas por tipo de agricultor entrevistado, na qual verificamos que o tipo 3BZ, de menor índice de utilização de práticas agroecológicas, apresenta os maiores valores de renda bruta, líquida, e total. Porém, coincidentemente, este mesmo tipo 3BZ, é o que apresenta também os maiores valores de área total e cultivada (Tabela 11).

Em oposição, na Tabela 10 observa-se para classe (1) de agricultores, que é a de maior índice de utilização de práticas agroecológicas, que os valores do tipo $\mathbf{1 A X}$, de renda bruta e líquida são os segundos maiores, e o de renda total é o terceiro maior, enquanto que os tipos $\mathbf{1 B X}$ e $\mathbf{1 B Y}$ apresentam os menores valores de renda bruta e líquida e respectivamente o menor e o terceiro menor valor de renda total.

Tabela 10: Valores médios de rendas (R \$/ano) por tipo de agricultor familiar da região centro-sul do Estado do Paraná entrevistado $(\mathrm{n}=35)$. *

\begin{tabular}{|c|c|c|c|c|c|c|}
\hline Tipologia** & $\begin{array}{c}\mathrm{N}^{0} \text { de } \\
\text { agricultores }\end{array}$ & $\begin{array}{l}\text { Renda } \\
\text { bruta }\end{array}$ & $\begin{array}{l}\text { Renda } \\
\text { líquida }\end{array}$ & $\begin{array}{c}\text { Renda de } \\
\text { auto consumo }\end{array}$ & $\begin{array}{c}\text { Renda } \\
\text { total }\end{array}$ & $\begin{array}{c}\text { Renda } \\
\text { per capita*** }\end{array}$ \\
\hline $1 \mathrm{AX}$ & 8 & \begin{tabular}{|c|}
$\mathbf{6 . 3 1 3}, 00$ \\
$\pm 5.687,00$
\end{tabular} & $\begin{array}{c}3.925,00 \\
\pm 4.075,00\end{array}$ & $\begin{array}{c}4.890,00 \\
\pm 4.439,00\end{array}$ & $\begin{array}{c}\mathbf{8 . 8 1 5 , 0 0} \\
\pm 5.039,00\end{array}$ & $\begin{array}{c}\mathbf{2 . 5 9 6 , 0 0} \\
\pm 1.414,00\end{array}$ \\
\hline $1 B X$ & 2 & $\begin{array}{l}2.250,00 \\
\pm 750,00\end{array}$ & $\begin{array}{l}1.700,00 \\
\pm 300,00\end{array}$ & $\begin{array}{c}\mathbf{5 . 8 7 4 , 0 0} \\
\pm 2.008,00\end{array}$ & $\begin{array}{c}7.574,00 \\
\pm 2.308,00\end{array}$ & $\begin{array}{l}2.070,00 \\
\pm 754,00\end{array}$ \\
\hline $1 \mathrm{BY}$ & $2 * * * *$ & $\begin{array}{c}900,00 \\
\pm 100,00\end{array}$ & $\begin{array}{c}650,00 \\
\pm 250,00\end{array}$ & $\begin{array}{c}3.746,00 \\
\pm 1.329,00\end{array}$ & $\begin{array}{c}4.396,00 \\
\pm 1.579,00\end{array}$ & $\begin{array}{l}1.559,00 \\
\pm 432,00\end{array}$ \\
\hline $2 \mathrm{AY}$ & 6 & $\begin{array}{c}3.967,00 \\
\pm 2.033,00\end{array}$ & $\begin{array}{c}2.717,00 \\
\pm 2.283,00\end{array}$ & $\begin{array}{c}3.702,00 \\
\pm 1.355,00\end{array}$ & $\begin{array}{c}\mathbf{6 . 4 1 9 , 0 0} \\
\pm 2.421,00\end{array}$ & $\begin{array}{c}3.049,00 \\
\pm 2.308,00\end{array}$ \\
\hline $2 \mathrm{BY}$ & 2 & $\begin{array}{c}3.650,00 \\
\pm 1.150,00\end{array}$ & $\begin{array}{l}2.650,00 \\
\pm 950,00\end{array}$ & $\begin{array}{c}6.262,00 \\
\pm 2.344,00\end{array}$ & $\begin{array}{c}8.912,00 \\
\pm 3.294,00\end{array}$ & $\begin{array}{c}3.565,00 \\
\pm 1.318,00\end{array}$ \\
\hline $2 \mathrm{BZ}$ & 5 & $\begin{array}{c}\mathbf{6 . 2 4 0 , 0 0} \\
\pm 13.760,00\end{array}$ & $\begin{array}{c}2.900,00 \\
\pm 5.100,00\end{array}$ & $\begin{array}{c}\mathbf{5 . 4 7 3 , 0 0} \\
\pm 1.857,00\end{array}$ & $\begin{array}{c}8.373,00 \\
\pm 5.071,00\end{array}$ & $\begin{array}{l}2.770,00 \\
\pm 529,00\end{array}$ \\
\hline $3 \mathrm{BZ}$ & 9 & $\begin{array}{c}\mathbf{9 . 7 3 3 , 0 0} \\
\pm 12.267,00 \\
\end{array}$ & $\begin{array}{c}\mathbf{5 . 6 8 8 , 0 0} \\
\pm 6.312,00 \\
\end{array}$ & $\mid \begin{array}{c}5.597,00 * * * * * \\
\pm 3.257,00\end{array}$ & $\begin{array}{r}10.030,00 \\
\pm 7.858,00 \\
\end{array}$ & $\begin{array}{c}3.517,00 \\
\pm 5.427,00 \\
\end{array}$ \\
\hline
\end{tabular}

* Fonte: Dados da pesquisa.

** Ver descrição dos tipos no Quadro 1.

*** Para o cálculo da renda per capita dividiu-se o valor da renda total pelo total de moradores, de cada unidade familiar de produção agrícola, computados como força de trabalho ativa. Para isto, considerou-se o total de moradores maiores de 18 anos que dedicavam tempo integral à atividade agrícola como uma unidade de trabalho, e os moradores com menos de 18 anos e mais de 14 anos, bem como os maiores de 18 anos que exerciam atividade em meio expediente fora da propriedade, como meia unidade de trabalho.

${ }^{3}$ Renda deste agricultor: renda bruta $=\mathrm{R} \$ 17.400,00$; renda líquida $=\mathrm{R} \$ 14.400,00$; renda de autoconsumo $=\mathrm{R} \$$ 9.054,00; renda total $=\mathrm{R} \$ 23.454,00$; renda per capita $=\mathrm{R} \$ 4.264,00$. 
**** Descartou-se um dos agricultores deste grupo cujo tamanho da área agrícola destoava do restante do grupo. ${ }^{3}$

***** Um dos agricultores utilizava somente área arrendada, fazendo isto integralmente com cultivo comercial, não gerando, portanto, renda de autoconsumo, tendo sido excluído do cálculo desta média.

Por outro lado, em relação à área cultivada, observa-se na Tabela 11 que os tipos da classe (1) apresentam os menores valores de área cultivada. No caso dos tipos 1BX e 1BY isto ocorre em função de serem os tipos com menor disponibilidade de terra (área total), mas no caso do tipo $\mathbf{1 A X}$, o menor percentual de área cultivada observado é devido aos 8 agricultores que o compõem, dedicarem maior tempo de trabalho ao cultivo de hortaliças, visando o mercado de produtos orgânicos, estando a totalidade dos agricultores deste tipo localizados nos municípios de União da Vitória e Palmeira, os quais, conforme mencionado anteriormente, possuíam política de incentivo à adoção de práticas agroecológicas.

Em relação ao tipo $\mathbf{2 A Y}$, cujos agricultores que compõem-no também utilizavam mercado de produtos orgânicos, verifica-se um maior percentual de área cultivada (Tabela 11), e isto deve-se ao fato de que os produtores apresentavam valores de área total menores, ao mesmo tempo em que mantinham a tradição de dedicar parte expressiva da área ao cultivo de milho e feijão, diferentemente dos agricultores do tipo $\mathbf{1 A X} .{ }^{4}$ Isto foi verificado mesmo junto a 4 agricultores do tipo $2 \mathrm{AY}$ que utilizavam o mercado de produtos orgânicos somente para a comercialização de hortaliças. ${ }^{5}$

Tabela 11: Valores médios de áreas por tipo de agricultor familiar da região centro-sul do Estado do Paraná entrevistado $(\mathrm{n}=35)$. $^{*}$

\begin{tabular}{c|c|c|c|c}
\hline \multirow{2}{*}{ Tipologia** } & N de agricultores & \multicolumn{2}{c}{ Área total (ha) Área cultivada (ha) } & $\begin{array}{c}\text { \% de área } \\
\text { cultivada }\end{array}$ \\
\hline 1AX & 8 & $\mathbf{3 3 , 0 4} \pm 46,82$ & $\mathbf{1 3 , 4 7} \pm 25,47$ & $\mathbf{5 1 , 0 5} \pm 40,05$ \\
1BX & 2 & $\mathbf{1 7 , 0 5} \pm 3,03$ & $\mathbf{1 6 , 0 5} \pm 1,53$ & $\mathbf{9 2 , 5 0} \pm 7,50$ \\
1BY & $2^{* * *}$ & $\mathbf{1 4 , 0 7} \pm 10,14$ & $\mathbf{8 , 5 3} \pm 5,86$ & $\mathbf{6 3 , 5 0} \pm 4,50$ \\
2AY & 6 & $\mathbf{2 5 , 8 1} \pm 8,88$ & $\mathbf{1 6 , 6 0} \pm 14,85$ & $\mathbf{6 3 , 2 8} \pm 29,52$ \\
2BY & 2 & $\mathbf{3 1 , 7 5} \pm 11,77$ & $\mathbf{2 2 , 7 8} \pm 10,08$ & $\mathbf{6 9 , 9 3} \pm 22,87$ \\
2BZ & 5 & $\mathbf{3 6 , 7 8} \pm 16,46$ & $\mathbf{1 8 , 0 5} \pm 4,34$ & $\mathbf{5 3 , 4 4} \pm 35,56$ \\
3BZ & 9 & $\mathbf{4 1 , 0 5} \pm 67,94$ & $\mathbf{3 0 , 0 9} \pm 59,54$ & $\mathbf{7 6 , 8 9} \pm 41,89$ \\
\hline
\end{tabular}

* Fonte: Dados da pesquisa. ** Ver descrição dos tipos no Quadro 1.

*** Descartou-se um dos agricultores deste grupo cujo tamanho da área agrícola destoava do restante do grupo. ${ }^{6}$

${ }^{4}$ Em função de terem adotado uma maior diversificação de cultivos, os agricultores do tipo $\mathbf{1 A X}$ reduziram a área cultivada com milho e feijão (tradição na região).

${ }^{5}$ Entre os dois restantes, um comercializava feijão, e outro, hortaliças e frutas. 
Percebe-se uma relação entre o grau de capitalização dos agricultores e a adoção de práticas agroecológicas, a qual aumenta à medida que se reduz o grau de capitalização. Isto pode ser enfatizado se considerarmos ainda que os valores médios de área total diminuem na medida em que aumenta o índice de utilização de práticas agroecológicas [classe (1) = 27,29 ha, classe $(2)=31,08$ ha; e classe $(3)=41,05$ há].

Esta realidade é consistente com o contexto específico da difusão das práticas agroecológicas na região. Estas práticas vêm sendo adotadas por agricultores que consideram-nas como uma alternativa de inovação compatível com a situação que vivenciam de baixa capitalização e de incapacidade de obtenção de recursos públicos (crédito subsidiado). Ou seja, o caráter intensivo em trabalho das práticas agroecológicas torna viável para estes agricultores - com grande disponibilidade de trabalho familiar - iniciar trajetórias de acumulação que, de outro modo, exigiriam capacidade de alavancagem de recursos que não dispõem.

No que se refere aos valores de renda per capita, verifica-se na Tabela 10 que os maiores valores foram para os tipos $\mathbf{2 B Y}$ e $\mathbf{3 B Z}$, e que para todos os tipos, excetuando-se o $\mathbf{1 B Y}$, a atividade agrícola estava assegurando uma remuneração superior a um salário mínimo ${ }^{7}$ por morador ativo das unidades familiares. Observando então a Figura 1, percebe-se que 7 agricultores $(20,0 \%)$ apresentavam renda per capita anual entre $\mathrm{R} \$ 1.000,00$ e R $\$ 1.999,99,18$ agricultores $(51,4 \%)$ entre $R$ \$ 2.000,00 e R $2.999,00,4$ agricultores $(11,4 \%)$ entre $\mathrm{R} \$ 3.000,00$ e $\mathrm{R} \$ 3.999,00,4$ agricultores $(11,4 \%)$ entre $\mathrm{R} \$ 4.000,00$ e $\mathrm{R} \$ 4.999,00,1$ agricultor $(2,9 \%)$ entre $\mathrm{R} \$ 5.000,00 \mathrm{e}$ $\mathrm{R} \$ 5.999,00$, e 1 agricultor (2,9\%) entre R\$ 8.000,00 e R\$ 8.999,00.

Nota-se ainda que as amplitudes de variação dos valores de renda per capita são bem maiores na classe (3) (R\$ 1.129,00 a 8.944,00), em oposição às classes (1) ( R \$ 1.127,00 a R \$ 4.264,00) e (2) (R \$ 2.108,00 a $\mathrm{R} \$ 5.357,00)$, ou seja, o risco financeiro dos agricultores das classes com maior índice de adoção de práticas agroecológicas é menor, possibilitando-lhes maior estabilidade de renda. Reforçando esta idéia, nenhum dos agricultores da classe (2) apresentava renda per capita inferior a

\footnotetext{
${ }^{6}$ Área deste agricultor: área total $=180,53$ ha; área cultivada $=43,80$ ha; proporção de área cultivada $=24,30 \%$.

7 À época das entrevistas o salário mínimo era de R\$ 150,00.
} 
$\mathrm{R} \$ 2.000,00$ anuais e, na classe (1), onde isto ocorria, o motivo estava relacionado à disponibilidade de terra agricultável, que variava de 2,62 ha a 14,52 ha (4 agricultores). Já na classe (3), enquanto 1 agricultor nesta situação possuía menos de 15,00 ha cultivados $(8,22$ ha), os outros 2 possuíam área acima deste valor (17,29 ha e 23,45 ha).

Figura 1: Renda per capita dos agricultores familiares da região centro-sul do Paraná entrevistados**

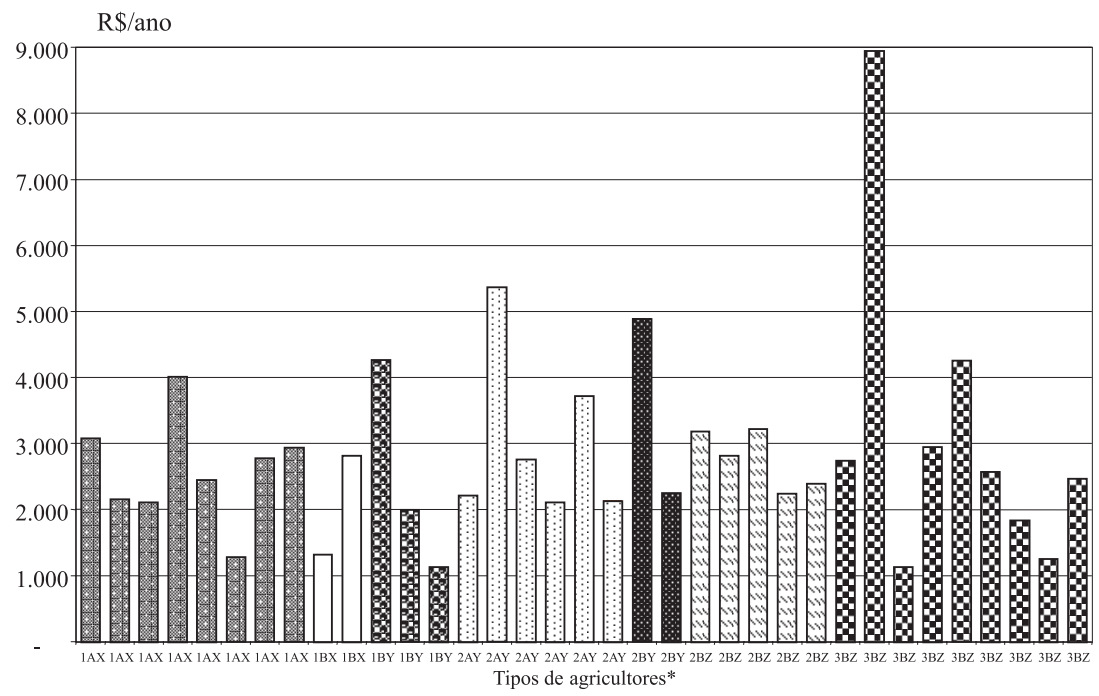

* Ver descrição dos tipos no Quadro 6. ** Fonte: Dados da pesquisa.

Enfatizando isto ainda mais, verifica-se que os tipos com maior índice de utilização de insumos agroquímicos, $\mathbf{2 B Z}$ e $\mathbf{3 B Z}$, são os que apresentam maiores diferenças entre os valores de renda bruta e líquida (R\$ 4.045,00 e R \$ 3.340,00, respectivamente). Na classe (1) essas diferenças nos tipos 1BX e 1BY são bem baixas ( $\mathrm{R} \$ 550,00$ e $\mathrm{R} \$ 250,00$, respectivamente), elevando-se um pouco apenas no tipo $\mathbf{A X}(\mathrm{R} \$ 2.388,00)$, motivada pela maior remuneração obtida em mercado de produtos orgânicos. Considera-se isto um resultado que indica um menor risco econômico da atividade agrícola dos agricultores com maior índice de adoção de práticas agroecológicas, caracterizando um potencial positivo da utilização de sistemas de produção agroecológicos como forma de reduzir o risco econômico à atividade agrícola. Há, desta forma, potencial positivo de 
utilização da agroecologia como referencial teórico e instrumental importante na implementação de processos de desenvolvimento agrícola sustentável que tenham a agricultura familiar como foco prioritário.

\section{Considerações finais}

Como foi dito na introdução, a estrutura familiar de produção impõe a necessidade de lógica diferente ao processo de desenvolvimento agrícola, tendo sido aqui caracterizado que a agroecologia é afeita a esta lógica, especialmente no que se refere a agricultores familiares de menor nível de capitalização, ao reduzir o risco econômico da atividade agrícola.

Neste processo, porém, a atuação do poder público, com políticas específicas voltadas para promover a difusão de práticas agroecológicas junto aos produtores familiares, é fundamental para que esta ocorra de forma mais ampla, face às limitações estruturais de iniciativas da sociedade, conforme aqui analisadas. Estas iniciativas cumpririam importante função ao mostrar a viabilidade da utilização do instrumental da agroecologia no processo de desenvolvimento agrícola sustentável destes agricultores, apresentando atuação voltada para a questão tecnológica e de organização dos produtores, de forma, a partir destas iniciativas, buscar o apoio das estruturas do Estado que permitam a ampliação do processo.

Este apoio deve ocorrer, principalmente, através de mecanismos de crédito agrícola adaptados à realidade da produção agrícola familiar, assistência técnica capacitada em agroecologia, aumentando a capilaridade do processo e a viabilização de canais de comercialização para uma produção agrícola diversificada, ao mesmo tempo em que aproxime produtores e consumidores, reduzindo o espaço de atuação de intermediários neste processo.

\section{7- Referências bibliográficas}

ALTIERI, M. A. Agroecologia - As bases científicas da agricultura alternativa. Rio de Janeiro: PTA-FASE, 1989. 237p.

BRANDENBURG, A. Agricultura Familiar, ONGs e Desenvolvimento Sustentável. Curitiba: Editora da UFPR, 1999. 326p. 
CANUTO, J. C. Agricultura Ecológica en Brasil - Perspectivas socioecológicas. Córdoba: Instituto de Sociología y Estudios Campesinos (ISEC) - Escuela Superior de Ingenieros Agrónomos y Montes (ETSIAM), 1998. 200p. Tese de Doutorado.

CARMO, M. S. do. A Produção Familiar como Locus Ideal da Agricultura Sustentável. Agricultura em São Paulo, São Paulo, v.45, n.1, p.1-15, 1998.

COSTA NETO, C. Agricultura Sustentável, Tecnologias e Sociedade. In: COSTA, L. F. de C.; MOREIRA, R. J.; BRUNO, R. (Ed.). Mundo Rural e Tempo Presente. Rio de Janeiro: Mauá, 1999. p. 299-321.

GARCIA FILHO, D. P. Análise Diagnóstico de Sistemas Agrários - Guia Metodológico. Disponível em: < http://www.incra.gov.br/_htm/serveinf/_htm/pubs/pubs.htm > . Acesso em 17 de março de 2003.

GUANZIROLI, C. E.; CARDIM, S. E. de C. S.; ROMEIRO, A. R.; DI SABBATO, A.; BUAINAIN, A. M.; REZENDE, G. C. de; BITTENCOURT, G. A.; VIEIRA, P. de T. L.; BARBOSA, M. D.; FERRAZ, E. P.; ALVES, M. A.; BAMPI, G. Novo Retrato da Agricultura Familiar - O Brasil redescoberto. Brasília: INCRA - FAO, 2000. 74 p. 